\section{(A) OPEN ACCESS}

- Additional material is published online only. To view please visit the journal online (http://dx.doi.org/10.1136/ heartjnl-2013-304963).

${ }^{1}$ Department of Social and Environmental Health Research, London School of Hygiene and Tropical Medicine, London, UK ${ }^{2}$ Department of

Non-Communicable Disease Epidemiology, London School of Hygiene and Tropical Medicine, London, UK

\section{Correspondence to} Dr Ai Milojevic, Department of Social and Environmental Health Research, London School of Hygiene \& Tropical Medicine, 15-17 Tavistock Place, London, WC1H 9SH, UK;

ai.milojevic@|shtm.ac.uk

Received 13 September 2013 Revised 21 February 2014 Accepted 16 March 2014 Published Online First 4 June 2014

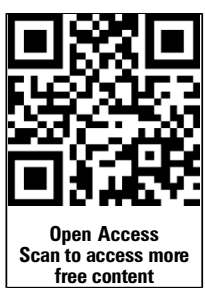

\section{Sinked}

- http://dx.doi.org/10.1136/ heartjnl-2014-305877

\section{CrossMark}

\section{To cite: Milojevic A,} Wilkinson $P$, Armstrong $B$, et al. Heart

2014;100:1093-1098.

\title{
Short-term effects of air pollution on a range of cardiovascular events in England and Wales: case-crossover analysis of the MINAP database, hospital admissions and mortality
}

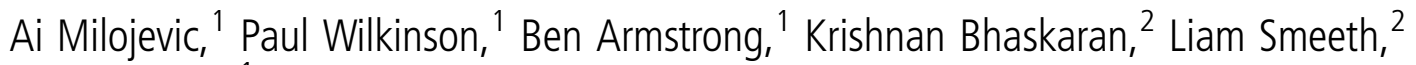 \\ Shakoor Hajat ${ }^{1}$
}

\begin{abstract}
Objective To inform potential pathophysiological mechanisms of air pollution effects on cardiovascular disease (CVD), we investigated short-term associations between ambient air pollution and a range of cardiovascular events from three national databases in England and Wales.
\end{abstract}

Methods Using a time-stratified case-crossover design, over 400000 myocardial infarction (MI) events from the Myocardial Ischaemia National Audit Project (MINAP) database, over 2 million CVD emergency hospital admissions and over 600000 CVD deaths were linked with daily mean concentrations of carbon monoxide (CO), nitrogen dioxide $\left(\mathrm{NO}_{2}\right)$, particulate matter less than $10 \mu \mathrm{m}$ in aerodynamic diameter $\left(\mathrm{PM}_{10}\right)$, particulate matter less than $2.5 \mu \mathrm{m}$ in aerodynamic diameter $\left(\mathrm{PM}_{2.5}\right)$ and sulfur dioxide $\left(\mathrm{SO}_{2}\right)$, and daily maximum of 8-hourly running mean of $\mathrm{O}_{3}$ measured at the nearest air pollution monitoring site to the place of residence. Pollutant effects were modelled using lags up to 4 days and adjusted for ambient temperature and day of week. Results For mortality, no CVD outcome analysed was clearly associated with any pollutant, except for $\mathrm{PM}_{2.5}$ with arrhythmias, atrial fibrillation and pulmonary embolism. With hospital admissions, only $\mathrm{NO}_{2}$ was associated with a raised risk: CVD $1.7 \%(95 \% \mathrm{Cl} 0.9$ to 2.6), non-MI CVD 2.0\% (1.1 to 2.9), arrhythmias $2.9 \%$ (0.6 to 5.2), atrial fibrillation $2.8 \%$ (0.3 to 5.4 ) and heart failure $4.4 \%$ (2.0 to 6.8) for a 10th-90th centile increase. With MINAP, only $\mathrm{NO}_{2}$ was associated with an increased risk of $\mathrm{Ml}$, which was specific to non-STelevation myocardial infarction (non-STEMIs): $3.6 \%$ (95\% Cl 0.4 to 6.9).

Conclusions This study found no clear evidence for pollution effects on STEMls and stroke, which ultimately represent thrombogenic processes, though it did for pulmonary embolism. The strongest associations with air pollution were observed with selected non-MI outcomes.

\section{INTRODUCTION}

Experimental and epidemiological studies have provided evidence of associations between air pollution and cardiovascular health. ${ }^{1-3}$ More pollution-related deaths occur from heart disease than from any other cause. A comparative risk assessment concluded that $7.4 \%$ of all cases of myocardial infarction (MI) is attributable to traffic-related air pollution, ${ }^{4}$ and a recent systematic literature review found associations with MI to be significant with all pollutants except $\mathrm{O}_{3}{ }^{5}$

Uncertainties remain, however, about the likely mechanisms of pollution-related cardiovascular disease (CVD). For example, hypotheses for particulate pollution include disturbance of the autonomic nervous system, ${ }^{6}$ changes in blood coagulability consequent to alveolar inflammation ${ }^{7}$ and the translocation of particles and/or their constituents into the blood. $^{3}$

This study aims to further current understanding of pathophysiological mechanisms by examining the strength and specificity of acute relationships between ambient air pollution and a range of CVD events. The key mechanistic question addressed is whether events of clear thrombotic origin, namely, acute MI, stroke and related outcomes, have a stronger association with air pollution than nonthrombotic outcomes.

\section{METHODS}

\section{Health data}

We analysed data from three databases: the Myocardial Ischaemia National Audit Project (MINAP) database, Hospital Episode Statistics (HES) and mortality (Office for National Statistics).

MINAP is a national register of admissions to hospital of patients with acute coronary syndrome/MI. All 230 acute hospitals in England and Wales contribute to the database, giving it theoretically complete geographical coverage. The database includes information on patient characteristics (including age, sex, smoking status), the timing of onset of symptoms, diagnostic data (ECG changes, enzyme markers, symptoms, etc.), previously recognised CVD, comorbidity (hypertension, diabetes, asthma, COPD, etc.), acute treatment, current therapy (such as aspirin or statins) and fatal outcome. Analysis consisted of all events during 2003-2009 that contained location information rounded to $100 \mathrm{~m}$ resolution of the centroid of the patient's enumeration district of residence. On average, enumeration districts contain 450 residents or 200 households. All patients with a discharge diagnosis of ST elevation MI (STEMI), non-ST elevation MI (non-STEMI), or troponinpositive acute coronary syndrome were included. Diagnosis of STEMI at discharge was based on clinical history, presence of cardiographic changes of ST elevation consistent with infarction and elevated 
enzyme or troponin levels. Diagnosis of non-STEMI was based on symptoms consistent with cardiac ischaemia, other cardiographic changes and elevated troponin levels.

The HES database consists of routine statistics on all admissions made to NHS hospitals in England and Wales. We analysed data on emergency admissions during 2003-2008. The geographical marker used for patient's residence was the population-weighted centroid of census ward, which, on average, contains 6000 people. Mortality data included all nationwide CVD deaths during 20032006 , with location based on the centroid of the postcode of residence. For both HES and mortality, the outcomes analysed were all CVD (ICD10 codes I00-I99), MI (I21-I23), all CVD except MI (referred to as non-MI CVD), stroke (I60-I69), ischaemic heart disease (IHD, I20-I25), chronic IHD (I25), pulmonary embolism (I26), atrioventricular conduction disorders (I44, I45), arrhythmias (I47, I48), atrial fibrillation (I48) and heart failure (I50).

\section{Exposure data}

Daily 24-h average values of particulate matter (particulate matter less than $10 \mu \mathrm{m}$ in aerodynamic diameter $\left(\mathrm{PM}_{10}\right)$ and particulate matter less than $2.5 \mu \mathrm{m}$ in aerodynamic diameter $\left.\left(\mathrm{PM}_{2.5}\right)\right)$, carbon monoxide (CO), nitrogen dioxide $\left(\mathrm{NO}_{2}\right)$ and sulfur dioxide $\left(\mathrm{SO}_{2}\right)$, and daily maximum values of 8 -h running mean of ozone $\left(\mathrm{O}_{3}\right)$, excluding roadside and kerbside sites, were obtained from monitoring stations run by the UK National Air Quality Information Archive (see online supplementary figure S1). Exposure was characterised for each health event using the nearest monitoring station to the place of residence, with the condition that exposure information was not missing on the event day and on $\geq 90 \%$ of days within each risk period (as defined in the analysis section). Based on preliminary analysis of season-specific correlations and mean differences between monitors at varying distances (see online supplementary figure S2), $50 \mathrm{~km}$ was set as the maximum distance within which to characterise exposure. In the rare situation where no station resided within $50 \mathrm{~km}$, that event was excluded from analysis.

Weather data were obtained for all monitoring stations via the British Atmospheric Data Centre (UK Meteorological Office MIDAS Land Surface Stations Data). Daily maximum and minimum temperatures were averaged to derive daily mean temperature. Linkage of health events to weather stations was based on the same algorithm as for air pollution.

\section{Analysis}

Short-term associations between air pollution and CVD events were assessed using a time-stratified case-crossover approach, whereby the day of each health event is considered as the case and all other days within the same month as controls. Lunar month was used for stratification to ensure periods of equal duration (ie, 28 days). Conditional logistic regression was used to assess associations, using pollutant measures lagged by up to 4 days (unconstrained distributed lag model). To maximise power, day-of-week effects were controlled for using indicator variables rather than the more common approach of matching. ${ }^{8}{ }^{9}$ However, for the two most numerous outcomes (all CVD and non-MI CVD admissions), this proved computationally limiting, and so matching was used instead.

The potentially confounding effects of temperature were controlled for using natural cubic splines (3 knots) of mean temperature, lagged by up to 2 weeks based on previous evidence. ${ }^{10}$ Potential autocorrelation in the event data was assessed and allowed for by introducing as explanatory variables residuals lagged by 1 and 2 days in all models. Effect modification of risk
Table 1 Summary of exposure data in 2003-2009

\begin{tabular}{llll}
\hline Pollutant & Number of monitors & Median (IQR) & $\begin{array}{l}\text { 10th-90th } \\
\text { centile range }\end{array}$ \\
\hline $\mathrm{CO}\left(\mathrm{mg} / \mathrm{m}^{3}\right)$ & 61 & $0.2(0.2-0.4)$ & 0.4 \\
$\mathrm{NO}_{2}\left(\mu \mathrm{g} / \mathrm{m}^{3}\right)$ & 93 & $24(13-37)$ & 45 \\
$\mathrm{O}_{3}\left(\mu \mathrm{g} / \mathrm{m}^{3}\right)$ & 82 & $61(46-76)$ & 61 \\
$\mathrm{PM}_{10}\left(\mu \mathrm{g} / \mathrm{m}^{3}\right)$ & 62 & $20(15-27)$ & 26 \\
$\mathrm{PM}_{2.5}\left(\mu \mathrm{g} / \mathrm{m}^{3}\right)$ & 46 & $10(7-15)$ & 16 \\
$\mathrm{SO}_{2}\left(\mu \mathrm{g} / \mathrm{m}^{3}\right)$ & 71 & $3.1(2-6)$ & 10.4 \\
Mean temperature (d/C) & 717 & $9.85(6.2-13.9)$ & 13.85 \\
\hline
\end{tabular}

$\mathrm{CO}$, carbon monoxide; $\mathrm{NO}_{2}$, nitrogen dioxide; $\mathrm{PM}_{2.5}$, particulate matter less than $2.5 \mu \mathrm{m}$ in aerodynamic diameter; $\mathrm{PM}_{10}$, particulate matter less than $10 \mu \mathrm{m}$ in aerodynamic diameter; $\mathrm{SO}_{2}$, sulfur dioxide.

by age and sex was explored, and for the MINAP analysis, additional modifiers were also examined.

Several sensitivity analyses were performed. First, where a strong pollution effect was observed, a second pollutant was incorporated to assess independent effects of the primary pollutant. Second, seasonal effects were examined by restricting analysis to summer months (June-August) for $\mathrm{O}_{3}$. Third, we considered a shorter lag structure of 0-1 days. Fourth, we allowed for day-of-week effects by matching rather than explicit control. Fifth, main analyses were repeated using robust SEs to allow for possible clustering by monitoring sites. Analyses were conducted using STATA V.12. Ethics approval was granted by the Ethics Committee of LSHTM.

\section{RESULTS}

Summary statistics for the exposure and health data are presented in tables 1 and 2, respectively.

\section{MINAP}

There were 452343 geographically coded MI events during the study period. Patients with non-STEMI events were older than STEMI patients (age $70+$ years $60.4 \%$ vs $41.6 \%$, respectively) and had higher rates of comorbidity (previous MI $30.1 \%$ vs

Table 2 Summary statistics and number of events for the MINAP registries in 2003-2009, emergency hospital admissions from HES in 2003-2008 and ONS mortality in 2003-2006

\begin{tabular}{llll}
\hline & MINAP & HES & ONS mortality \\
\hline Age (years): median (IQR) & $71(60-81)$ & $73(60-82)$ & $82(74-88)$ \\
Male (\%) & 65 & 54 & 48 \\
All CVD events (N) & & 2867473 & 752004 \\
$\quad$ Stroke & & 461845 & 209294 \\
IHD & & 967677 & 361738 \\
$\quad$ MI & 452343 & 417833 & 151483 \\
$\quad$ Chronic IHD & & 85989 & 208505 \\
Arrhythmias & 379605 & 11703 \\
$\quad$ Atrial fibrillation & & 310568 & 11587 \\
AVCD & & 47666 & 463 \\
Pulmonary embolism & & 88988 & 12520 \\
Heart failure & 335495 & 37033 \\
Sudden (cardiac) death & & 532 & 90 \\
Pulmonary heart disease & & 2000 & 603 \\
\hline
\end{tabular}

AVCD, atrioventricular conduction disorders; CVD, cardiovascular disease; HES, Hospital Episode Statistics; IHD, ischaemic heart disease; MI, myocardial infarction; MINAP, Myocardial Ischaemia National Audit Project; ONS, Office for National Statistics. 
$14.4 \%$; previous angina $35.9 \%$ vs $16.3 \%$; previous hypertension $47.4 \%$ vs $36.4 \%$; and diabetes $20.8 \%$ vs $11.9 \%$, see online supplementary table S1).

Table 3 presents the percent change in MI risk for 10th-90th centile increases in pollutant measures, for all MI events and separately for STEMI (approximately $42 \%$ of the cases) and non-STEMI diagnosis. In general, there was very little evidence of a pollution effect on MI risk, with as many negative effect estimates as positive. The strongest evidence for any adverse effect was with $\mathrm{NO}_{2}$, where a 10th-90th centile increase was associated with a $2.4 \%$ increase $(95 \%$ CI 0.3 to $4.5 \%$ ) in overall MI risk, and with $\mathrm{SO}_{2}$ where the corresponding increase was $1.7 \%(-0.1$ to $3.4 \%)$. Associations for these two pollutants appeared to be stronger for non-STEMI compared with STEMI events. There were few factors that consistently modified the risk of $\mathrm{NO}_{2}$ or $\mathrm{SO}_{2}$ on either STEMIs or non-STEMIs (see online supplementary figures S3 and S4). The effects on non-STEMIs were significantly greater when the outcome was fatal compared with non-fatal. Those aged $70+$ years were also at heightened risk, and those with a previous percutaneous coronary intervention were at reduced risk of MI following exposure to either pollutant.

\section{Hospital admissions}

Figure 1 presents effects on emergency hospital admissions. Only $\mathrm{NO}_{2}$ was associated with higher risk of admission for any of the causes: a 10th-90th centile change was associated with an increase of $1.7 \%$ (95\% CI 0.9 to $2.6 \%)$ for CVD, $2.0 \%(1.1$ to 2.9 ) non-MI CVD, $2.9 \%$ (0.6 to $5.2 \%$ ) arrhythmias, $2.8 \%$ (0.3 to $5.4 \%)$ atrial fibrillation and $4.4 \%$ (2.0 to $6.8 \%)$ heart failure. Such $\mathrm{NO}_{2}$ association was significantly greater in females and those aged 70+ years for non-MI admissions and in females for arrhythmia (see online supplementary table S2). For all outcomes, $\mathrm{PM}_{2.5}$ or $\mathrm{PM}_{10}$ showed little evidence of increased risk of admissions, and indeed, in many cases, the risks were negative. Ozone was associated with reduced admissions for CVD, non-MI CVD and IHD.

\section{Mortality}

Figure 2 presents effects on mortality outcomes. None were clearly associated with pollutants, with the exception of $\mathrm{PM}_{2.5}$ on some outcomes: a 10th-90th centile change was associated with an increase of 21\% (95\% CI 3.9 to $40.8 \%$ ) for arrhythmias, $21 \%$ (3.9 to $41 \%$ ) atrial fibrillation and $20.5 \%$ (3.5 to $39.7 \%$ ) pulmonary embolism. For all CVD deaths and deaths from $\mathrm{IHD}, \mathrm{PM}_{2.5}$ and $\mathrm{O}_{3}$ risk was significantly raised among women (see online supplementary table S3). Also, those aged $70+$ years were at significantly greater risk from $\mathrm{O}_{3}$ exposure on all CVD and IHD deaths.

\section{Sensitivity analyses}

The above results were robust to (i) adjustment for a second pollutant, except $\mathrm{PM}_{2.5}$ effects on mortality, which were reduced by $10-15 \%$ and rendered non-significant after adjustment for $\mathrm{NO}_{2}$; (ii) summer-specific effects for $\mathrm{O}_{3}$ in MINAP models; (iii) effects assessed at just lags $0-1$ days, except $\mathrm{PM}_{2.5}$ on admissions for arrhythmias (see online supplementary figure S5); (iv) adjustment for day-of-week by matching; and (v) clustering effects by monitoring sites.

\section{DISCUSSION}

\section{Summary of findings}

We observed little acute effect of ambient air pollution on STEMIs or stroke. $\mathrm{NO}_{2}$ was associated with admissions for CVD overall, non-MI CVD, arrhythmias including atrial fibrillation and heart failure. $\mathrm{PM}_{2.5}$ showed some adverse effects on all CVD deaths, arrhythmias and pulmonary embolism. In general, effects of $\mathrm{NO}_{2}$ on hospital admissions and $\mathrm{PM}_{2.5}$ on mortality were higher in those over 70 years and in females, although sex differences may also reflect differences in the age distribution.

\section{Comparison with other studies}

Our results are mostly consistent with a previous analysis of the MINAP database, which observed a detrimental effect of pollution in 1-6 h but with little net effect at the daily level. ${ }^{11}$ Their findings suggest that any evident initial risk from pollution exposure may have been demonstrating a bringing forward of MI events in already vulnerable individuals (displacement by a few hours). However, our sensitivity analysis showed an increased effect of $\mathrm{NO}_{2}$ and $\mathrm{SO}_{2}$ on non-STEMI at lags 0 4 days compared with lags $0-1$ days, suggesting little evidence for displacement at the daily level.

The general lack of a pollution effect on MI (especially STEMI) risk in the current study is not unexpected. Although a recent systematic review reported most air pollutants were associated with a short-term increase in MI risk, ${ }^{5}$ a previous review revealed less than half of the identified studies found clear evidence of raised MI risk from exposure to pollutants. ${ }^{12}$ Furthermore, the studies that did not detect a detrimental effect tended to be those that had better temperature control (eg,

Table 3 Number of events linked to each pollutant data and per cent change in risk* of MI for all MI, STEMI and non-STEMI diagnoses associated with increased levels of pollutants at lags $0-4$ days

\begin{tabular}{|c|c|c|c|c|c|c|c|}
\hline \multirow{3}{*}{$\begin{array}{l}\text { Pollutant } \\
\text { CO }\end{array}$} & \multirow{3}{*}{$\begin{array}{l}\text { Events } \\
343914\end{array}$} & \multirow{2}{*}{\multicolumn{2}{|c|}{$\begin{array}{l}\text { All MI } \\
\% \text { change }(95 \% \mathrm{Cl})\end{array}$}} & \multirow{2}{*}{\multicolumn{2}{|c|}{$\begin{array}{l}\text { STEMI } \\
\% \text { change }(95 \% \mathrm{Cl})\end{array}$}} & \multirow{2}{*}{\multicolumn{2}{|c|}{$\begin{array}{l}\text { Non-STEMI } \\
\% \text { change }(95 \% \mathrm{Cl})\end{array}$}} \\
\hline & & & & & & & \\
\hline & & 0.2 & $(-1.4$ to 1.9$)$ & 1.4 & $(-1.2$ to 3.9$)$ & -0.6 & (-2.8 to 1.6$)$ \\
\hline $\mathrm{NO}_{2}$ & 405799 & 2.4 & (0.3 to 4.5 ) & 1.4 & $(-1.8$ to 4.6$)$ & 3.1 & (0.3 to 6.0 ) \\
\hline $\mathrm{O}_{3}$ & 410341 & -1.4 & ( -3.1 to 0.4$)$ & -2.8 & $(-5.5$ to -0.1$)$ & -0.3 & (-2.6 to 2.0$)$ \\
\hline $\mathrm{PM}_{10}$ & 365151 & -0.6 & $(-1.9$ to 0.7$)$ & -0.5 & $(-2.5$ to 1.5$)$ & -0.6 & $(-2.3$ to 1.1$)$ \\
\hline $\mathrm{PM}_{2.5}$ & 134964 & -0.4 & $(-2.4$ to 1.6$)$ & -2.7 & $(-5.6$ to 0.3$)$ & 1.2 & $(-1.4$ to 3.8$)$ \\
\hline $\mathrm{SO}_{2}$ & 380743 & 1.7 & $(-0.1$ to 3.4$)$ & 0.8 & $(-1.9$ to 3.5$)$ & 2.3 & (0.0 to 4.7 ) \\
\hline
\end{tabular}

MI, myocardial infarction; STEMI, ST-elevation Mls.

*Per cent change in risk for a 10th-90th centile change in pollutant in 2003-2009.

Data source: MINAP registry, 2003-2009.

$\mathrm{CO}$, carbon monoxide; MINAP, Myocardial Ischaemia National Audit Project; $\mathrm{NO}_{2}$, nitrogen dioxide; $\mathrm{PM}_{2.5}$, particulate matter less than $2.5 \mu \mathrm{m}$ in aerodynamic diameter; $\mathrm{PM}_{10}$

particulate matter less than $10 \mu \mathrm{m}$ in aerodynamic diameter; $\mathrm{SO}_{2}$, sulfur dioxide. 


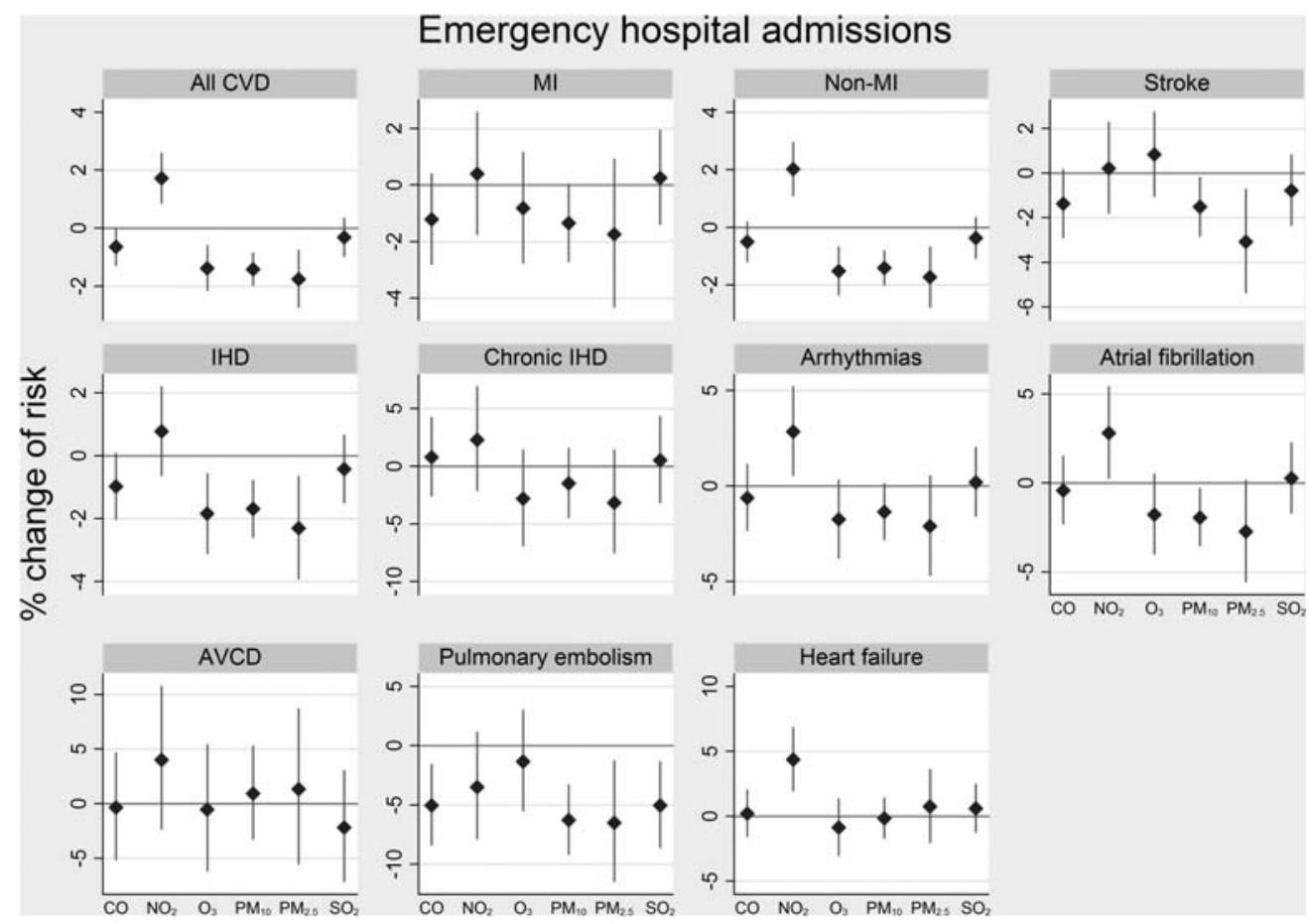

Figure 1 Per cent change $(95 \% \mathrm{Cl})$ in risk of emergency cardiovascular admissions for a 10th-90th centile change in pollutant at lags $0-4$ days. 10th-90th centile ranges in pollutants for 2003-2008. AVCD, atrioventricular conduction disorder; MI, myocardial infarction; IHD, ischaemic heart disease. Data source: Hospital Episode Statistics database, 2003-2008.

considered lagged effects) and also were more likely to have separate validation of MI diagnosis. Another comprehensive review of CVD outcomes in relation to particulate matter indicated that results related to thrombosis/coagulation were variable due to differences in study designs, patients and biomarkers evaluated, but that adverse effects were most consistent among high-risk groups. ${ }^{3}$ However, we observed little effect of $\mathrm{PM}_{10}$ or $\mathrm{PM}_{2.5}$ specifically on MI events, even among high-risk individuals.

Contrary to previous studies, ${ }^{13-16}$ we observed little effect of pollutants on cardiovascular mortality, although some adverse $\mathrm{PM}_{2.5}$ effect was detected. Results from a follow-up study of Medicare patients ${ }^{17}$ indicated that smaller particles and their components derived from combustion sources (ie, $\mathrm{PM}_{2.5}$ ) are principally responsible for cardiovascular hospitalisations attributed to the combination of fine and coarse particles (ie, $\mathrm{PM}_{10}$ ). In our study, adverse effects of $\mathrm{PM}_{2.5}$ or $\mathrm{PM}_{10}$ on cardiovascular admissions were not apparent but strong $\mathrm{NO}_{2}$ effects were observed, particularly with non-MI CVD, arrhythmias including atrial fibrillation and heart failure. Although $\mathrm{NO}_{2}$ and $\mathrm{PM}$ measures are correlated (see online supplementary table S4), the strong $\mathrm{NO}_{2}$ effect on admissions persisted after adjustment for $\mathrm{PM}_{2.5}$. By contrast, the $\mathrm{PM}_{2.5}$ effect on mortality outcomes was somewhat reduced when $\mathrm{NO}_{2}$ was adjusted for. Previous work from Europe has highlighted that higher $\mathrm{NO}_{2}$ levels can be associated with larger $\mathrm{PM}_{10}$ effects on mortality. ${ }^{18}$ Differences between our results for mortality and hospital admissions outcomes may have been explained by a smaller set of linked mortality events compared with admissions, with possibly different patient characteristics. However, our $\mathrm{NO}_{2}$ effect on admissions was even greater when restricted to the subset of patients who could be successfully linked to a $\mathrm{PM}_{2.5}$ monitor also. In addition, $\mathrm{PM}_{2.5}$ appeared to increase the risk of death where the recorded underlying cause was an arrhythmia, including atrial fibrillation (though the proximate cause may have been a complication of such arrhythmia), and pulmonary embolism, but reduced hospitalisation for these causes. One possible explanation might be those effects are rapid and so vulnerable individuals may bypass medical presentation, as suggested by Rich et al. $^{19}$ Curiously, our sensitivity analysis showed an adverse effect of $\mathrm{PM}_{2.5}$ at lags $0-1$ days, which was then protective by lags 0-4 days.

A protective effect was also observed with $\mathrm{O}_{3}$ on some CVD outcomes, which has also been observed by previous studies. ${ }^{12}$ This effect persisted in two-pollutant models and also when MINAP events were restricted to just the summer months when $\mathrm{O}_{3}$ concentrations are at their highest. Such patterns may be due to its negative correlation with an unmeasured pollutant or may reflect the fact that $\mathrm{O}_{3}$ is highly reactive and so measurements based on outdoor monitors may not be a good proxy for personal exposure.

\section{Biological mechanisms}

Observational and experimental studies have proposed a number of pathways to explain how air pollution may affect the cardiovascular system. The main candidate hypotheses are the disruption of the autonomic nervous system and/or an inflammatory response. ${ }^{20}$ There is evidence that the specific biological mechanisms that then trigger cardiovascular events include vascular dysfunction or vasoconstriction, enhanced thrombosis or coagulation potential, elevated arterial blood pressure, enhanced atherosclerosis or plaque vulnerability, and arrhythmias. ${ }^{3}$

Animal studies show that air pollutants affect the cardiac autonomic nervous system. ${ }^{21}$ Exposure of dogs to concentrated ambient particles leads to alterations in heart rate variability and thus a disturbance in cardiac autonomic control. ${ }^{22}$ However, in human experimental studies, heart rate variability or heart rhythm has not been found to be associated with diesel exhaust fumes, ${ }^{23}{ }^{24}$ which is discrepant with evidence from observational studies. $^{25}$ 


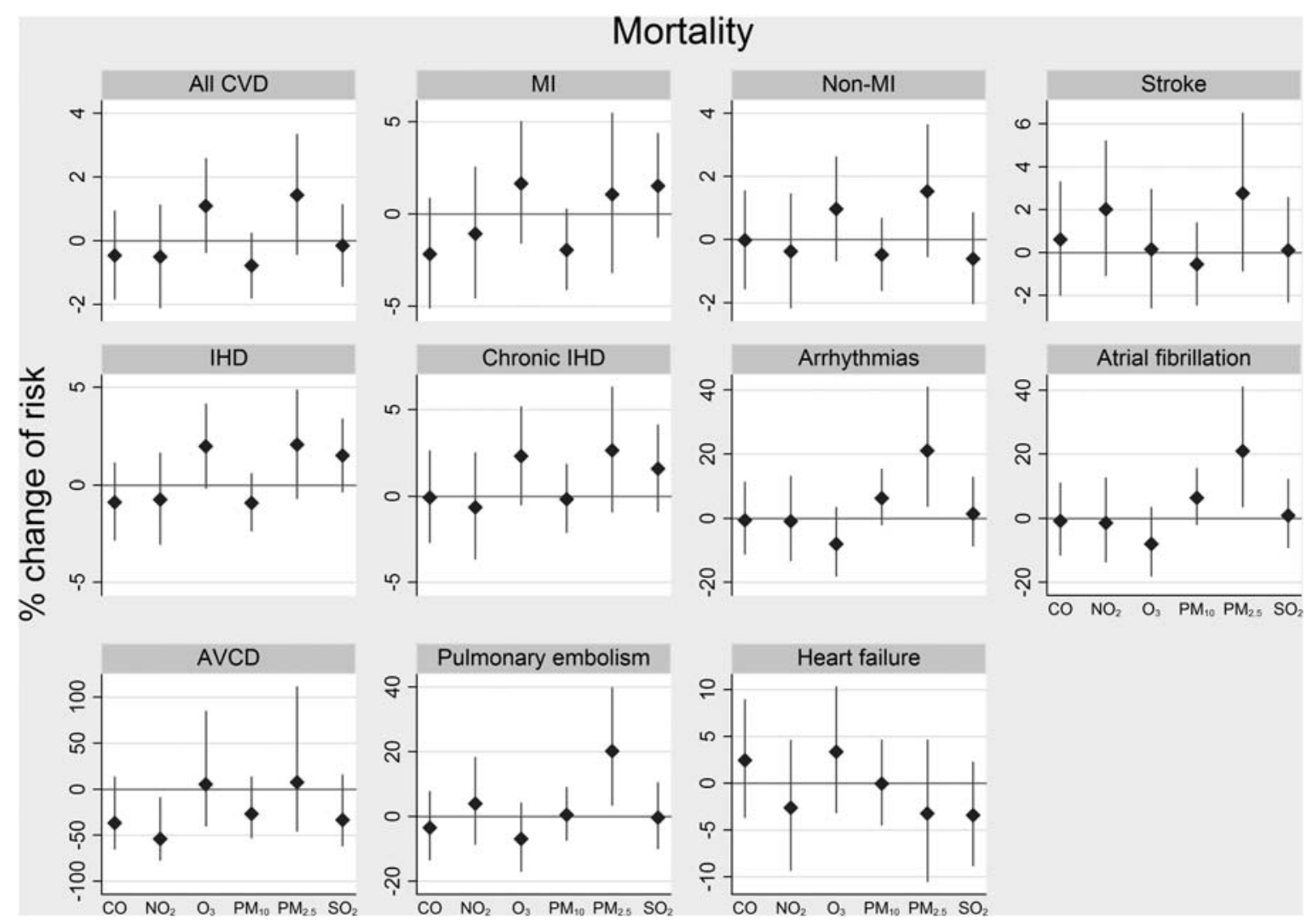

Figure 2 Per cent change $(95 \% \mathrm{Cl})$ in risk of cardiovascular mortality for a 10th-90th centile change in pollutant at lags $0-4$ days. 10th-90th centile ranges in pollutants for 2003-2006. AVCD, atrioventricular conduction disorder; MI, myocardial infarction; IHD, ischaemic heart disease. Data source: Office of National Statistics mortality registry, 2003-2006.

Although it is likely that air pollution affects cardiovascular health via multiple mechanisms, the lack of pollution effects on STEMIs and stroke, but the stronger associations with selected non-MI outcomes in the current study, suggests that pollution effects on cardiovascular health may in part be mediated by non-thrombotic pathways. However, thrombogenic mechanisms may still operate and are the most likely explanation for the observed associations with pulmonary embolism, for example.

Besides, we cannot exclude the possibility of the consequences of systemic inflammation occurring over longer time periods, which may then predispose vulnerable individuals to future cardiovascular events.

\section{Strengths and limitations}

A major strength of this study is the national coverage of a wide range of CVD outcomes. A previous study using a similarly large population in 204 US counties only considered elderly patients in urban areas. ${ }^{26}$ In our study, all acute hospitals in England and Wales are included on the MINAP database and thus should not under-represent any subgroups of the population, including those living in rural areas, except with $\mathrm{PM}_{2.5}$ (discussed below). An additional strength is the specific case definitions of MI in the MINAP database using large amounts of clinical information.

There are some limitations. First, the consistency of results on MI using MINAP and HES data is to be expected as there will be considerable overlap between the two databases. Also, no information is available on those MIs that result in death before admission. It is therefore possible that pollution effects may be missed if they result in fatal heart attacks before coming to medical attention, although there is no reason to suspect such a specific effect that is not observed in MI patients who reach hospital. More extensive analysis of long-term exposure effects on mortality among MINAP patients has been reported separately. ${ }^{27}$ Second, we used fixed monitoring sites to represent air pollution and so may not accurately reflect personal exposure. However, we excluded roadside and kerbside monitors and correlations between other stations were generally high within $50 \mathrm{~km}$ of each other. A $50 \mathrm{~km}$ limit ensured that a high number of CVD events were successfully linked to exposure (over $80 \%$ for all pollutants except $\mathrm{PM}_{2.5}$ ). It is possible that some exposure misclassification may have contributed to the largely null results and that restricting analyses to events substantially nearer the monitoring sites may have revealed stronger associations. However, a previous analysis of MINAP using pollution and event data restricted to within the major conurbations also observed little pollution effect over a 3-day period. ${ }^{11}$ Third, the number of national $\mathrm{PM}_{2.5}$ monitoring sites is limited in the UK and most of the sites are located in urban residential areas. Thus, our $\mathrm{PM}_{2.5}$ effects may not be representative of those living in other settings. Ultrafine particles, black carbon or $\mathrm{NO}_{\mathrm{x}}$ may be better indicators of primary combustion particles compared with $\mathrm{PM}_{10}$ and $\mathrm{PM}_{2.5}$ from urban background stations, which also reflect secondary PM and road dust. However, there is no such national monitoring network in the UK. Here we note that the effects of black carbon may not be dissimilar to $\mathrm{PM}_{2.5}$ or $\mathrm{PM}_{10}$ when considered in terms of a percentile change, as previously reported. ${ }^{28}$ Finally, the meaning of specific pollutant concentration is not simple to interpret as each typically acts as an indicator of a mixture as well a specific pollutant, with the latter meaning changing in two-pollutant models. 


\section{CONCLUSIONS}

This study found no clear evidence for pollution effects on STEMIs and stroke, which ultimately represent thrombogenic processes, though it did for pulmonary embolism. The strongest associations with air pollution were observed with selected non-MI outcomes. Experimental studies with tightly controlled pollution mixes, in addition to large-scale observational studies such as this, are needed to help elucidate mechanistic pathways further. Elderly people and hospital patients with chronic IHD or arrhythmias are observed to be at particular risk, which could help inform intervention strategies.

\section{Key messages}

What is already known on this subject?

- High levels of some air pollutants are associated with increased risk of cardiovascular health outcomes.

- The likely mechanisms of pollution-related cardiovascular disease are uncertain.

What this study adds?

- Short-term exposure to $\mathrm{NO}_{2}$ and $\mathrm{PM}_{2.5}$ has adverse effects on selected non-MI outcomes, especially arrhythmia.

- This study found no clear evidence for pollution effects on STEMls and stroke, which ultimately represent thrombogenic processes, though it did for pulmonary embolism.

- Elderly people and hospital patients with chronic IHD or arrhythmias are observed to be at particular risk of MI.

How might this impact on clinical practice?

- This study provides further evidence on current understanding of pathophysiological mechanisms by examining the strength and specificity of acute relationships between ambient air pollution and a range of cardiovascular disease events.

- Subgroup analyses using detailed patient information of MINAP database might help inform intervention strategies.

Correction notice The license of this article has also changed since publication to CC BY 4.0.

Acknowledgements We thank all those participating in the Myocardial Ischaemia National Audit Project (MINAP) and especially those staff responsible for data collection. All analyses were conducted with the aid of the high-power computing facilities provided by the London School of Hygiene \& Tropical Medicine.

Contributors $A M, P W, B A, K B, L S$ and $S H$ were involved in the study design. AM did preanalysis and main statistical analysis regarding the HES data and ONS mortality data. SH did the MINAP analysis. AM wrote the first draft and SH, PW, $B A, K B$, LS contributed to further drafts. AM and SH are the guarantors for the study and had full access to all of the data in the study.

Funding This is an independent report commissioned and funded by the Policy Research Programme in the Department of Health (Reference 002/0028). The views expressed are not necessarily those of the Department. KB is supported by a National Institute for Health Research postdoctoral fellowship (grant number NIHR-PDF-2011-04-007) and LS by a Wellcome Trust Senior Research Fellowship in Clinical Science grant number 098504/Z/12/Z

Competing interests None.

Ethics approval London School of Hygiene and Tropical Medicine.

Provenance and peer review Not commissioned; externally peer reviewed.

Open Access This is an Open Access article distributed in accordance with the terms of the Creative Commons Attribution (CC BY 4.0) license, which permits others to distribute, remix, adapt and build upon this work, for commercial use, provided the original work is properly cited. See: http://creativecommons.org/ licenses/by/4.0/

\section{REFERENCES}

1 Ayres JG. Cardiovascular disease and air pollution: a report by the Committee on the Medical Effects of Air Pollution. Department of Health, 2006.

2 Brook RD, Franklin B, Cascio W, et al. Air pollution and cardiovascular disease: a statement for healthcare professionals from the expert panel on population and prevention science of the American Heart Association. Circulation 2004; 109:2655-71.

3 Brook RD, Rajagopalan S, Pope CA 3rd, et al. Particulate matter air pollution and cardiovascular disease: an update to the scientific statement from the American Heart Association. Circulation 2010;121:2331-78.

4 Nawrot TS, Perez L, Kunzli N, et al. Public health importance of triggers of myocardial infarction: a comparative risk assessment. Lancet 2011;377:732-40.

5 Mustafic $\mathrm{H}$, Jabre $\mathrm{P}$, Caussin $\mathrm{C}$, et al. Main air pollutants and myocardial infarction: a systematic review and meta-analysis. JAMA 2012;307:713-21.

6 Peters A. Particulate matter and heart disease: evidence from epidemiological studies. Toxicol Appl Pharmacol 2005;207:477-82.

7 Seaton A, MacNee W, Donaldson K, et al. Particulate air pollution and acute health effects. Lancet 1995;345:176-8.

8 Janes $\mathrm{H}$, Sheppard L, Lumley T. Case-crossover analyses of air pollution exposure data: referent selection strategies and their implications for bias. Epidemiology 2005; 16:717-26.

9 Schwartz J. Is the association of airborne particles with daily deaths confounded by gaseous air pollutants? An approach to control by matching. Environ Health Perspect 2004;112:557-61.

10 Bhaskaran K, Hajat S, Haines A, et al. Short term effects of temperature on risk of myocardial infarction in England and Wales: time series regression analysis of the Myocardial Ischaemia National Audit Project (MINAP) registry. BMJ 2010;341:c3823.

11 Bhaskaran K, Hajat S, Armstrong B, et al. The effects of hourly differences in air pollution on the risk of myocardial infarction: case crossover analysis of the MINAP database. BMJ 2011;343:d5531.

12 Bhaskaran K, Hajat S, Haines A, et al. Effects of air pollution on the incidence of myocardial infarction. Heart 2009;95:1746-59.

13 Peng RD, Dominici F, Pastor-Barriuso R, et al. Seasonal analyses of air pollution and mortality in 100 US cities. Am J Epidemiol 2005;161:585-94

14 Samet JM, Dominici F, Curriero FC, et al. Fine particulate air pollution and mortality in 20 U.S. cities, 1987-1994. N Engl J Med 2000;343:1742-9.

15 Samoli $E$, Aga $E$, Touloumi $G$, et al. Short-term effects of nitrogen dioxide on mortality: an analysis within the APHEA project. Eur Respir J 2006;27:1129-38.

16 Samoli E, Touloumi G, Schwartz J, et al. Short-term effects of carbon monoxide on mortality: an analysis within the APHEA project. Environ Health Perspect 2007:115:1578-83.

17 Peng RD, Chang HH, Bell ML, et al. Coarse particulate matter air pollution and hospital admissions for cardiovascular and respiratory diseases among Medicare patients. JAMA 2008;299:2172-9.

18 Samoli E, Peng R, Ramsay T, et al. Acute effects of ambient particulate matter on mortality in Europe and North America: results from the APHENA study. Environ Health Perspect 2008;116:1480-6.

19 Rich DQ, Mittleman MA, Link MS, et al. Increased risk of paroxysmal atrial fibrillation episodes associated with acute increases in ambient air pollution. Environ Health Perspect 2006;114:120-3.

20 Bhaskaran K, Wilkinson P, Smeeth L. Cardiovascular consequences of air pollution: what are the mechanisms? Heart 2011;97:519-20.

21 Shrey K, Suchit A, Deepika D, et al. Air pollutants: the key stages in the pathway towards the development of cardiovascular disorders. Environ Toxicol Pharmacol 2011:31:1-9.

22 Godleski JJ, Verrier RL, Koutrakis P, et al. Mechanisms of morbidity and mortality from exposure to ambient air particles. Rese Rep Health Eff Inst 2000:5-88; discussion 89-103.

23 Mills NL, Finlayson AE, Gonzalez MC, et al. Diesel exhaust inhalation does not affect heart rhythm or heart rate variability. Heart 2011;97:544-50.

24 Peretz A, Kaufman JD, Trenga CA, et al. Effects of diesel exhaust inhalation on heart rate variability in human volunteers. Environ Res 2008;107:178-84.

25 Dockery DW, Luttmann-Gibson H, Rich DQ, et al. Association of air pollution with increased incidence of ventricular tachyarrhythmias recorded by implanted cardioverter defibrillators. Environ Health Perspect 2005;113:670-4.

26 Dominici F, Peng RD, Bell ML, et al. Fine particulate air pollution and hospital admission for cardiovascular and respiratory diseases. JAMA 2006;295:1127-34.

27 Tonne C, Wilkinson P. Long-term exposure to air pollution is associated with survival following acute coronary syndrome. Eur Heart J 2013;34:1306-11.

28 Janssen NA, Hoek G, Simic-Lawson M, et al. Black carbon as an additional indicator of the adverse health effects of airborne particles compared with PM10 and PM2.5. Environ Health Perspect 2011;119:1691-9. 


\section{Corrections}

Milojevic A, Wilkinson P, Armstrong B, et al. Short-term effects of air pollution on a range of cardiovascular events in England and Wales: case-crossover analysis of the MINAP database, hospital admissions and mortality. Heart 2013;100:1093-8. This paper should have been published under a CC-BY license and not a CC-BY-NY license.

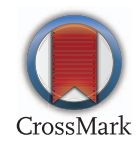

Heart 2015:101:162.

doi:10.1136/heartjnl-2013-304963corr1 